\title{
Effect of monomer concentration on the performance of Polyaniline based redox capacitors
}

\author{
W.A.D.S.S. Weerasinghe, K.P. Vidanapathirana* and Kumudu S. Perera \\ Department of Electronics, Faculty of Applied Sciences, Wayamba University of Sri Lanka, Kuliyapitiya, 60200 \\ Sri Lanka
}

Received:26/04/2017; Accepted: 26/07/2017

\begin{abstract}
Supercapacitors are promising alternatives for answering the thirst for ever increasing demand for power. They bridge the gap between the batteries and the conventional capacitors. Redox capacitors in the family of supercapacitors consist of conducting polymers or transition metal oxide electrodes. In this study, symmetric redox capacitors have been fabricated utilizing Polyaniline electrodes and a Polyvinylidenefluoride based gel polymer electrolyte. The effect of aniline concentration on the performance of redox capacitors was investigated. Aniline concentration was varied from $0.20 \mathrm{M}$ to 0.50 M. Capacitors were characterized using Electrochemical Impedance Spectroscopy, Cyclic Voltammetry and Galvanostatic Charge-Discharge tests. Redox capacitor with $0.40 \mathrm{M}$ aniline concentration showed the highest performance. From EIS measurements it was shown that the lowest relaxation time was $0.22 \mathrm{~s}$. This implies that $0.40 \mathrm{M}$ aniline system has the fastest ion movement behavior. Cyclic Voltammetry (CV) test of this capacitor resulted $81 \%$ of specific capacity retention between the $1^{\text {st }}$ and the $200^{\text {th }}$ cycle. Galvanostatic ChargeDischarge (GCD) for 1000 cycles showed an average discharging capacity of $323 \mathrm{~F} \mathrm{~g}^{-1}$, power density of $760 \mathrm{~W} \mathrm{~kg}^{-1}$ and energy density of $6.5 \mathrm{Wh} \mathrm{kg}^{-1}$. The results of this study confirm that aniline concentration has a significant effect on the performance of PANI films when they are served as electrodes in redox capacitors.
\end{abstract}

Keywords: Conducting polymer, Polyaniline, redox capacitor, gel polymer electrolyte, Electrochemical Impedance Spectroscopy.

\section{INTRODUCTION}

Current and emerging electronic devices have exacerbated the need for improvements in performance of energy storage devices. In the past, batteries and capacitors dominated the types of energy storage devices. With the advancement in the science and technology, supercapacitors (SCs) have emerged as a new type of energy storage devices which are cable of delivering high power within a short period of time (Kousksou et al., 2014). SCs have been categorized into two general classes based on the type of electrode materials employed and the charge storage mechanism at the electrodeelectrolyte interfaces (Hashmi et al.,2007). They are Electrochemical Double Layer Capacitors (EDLCs) and Redox Capacitors. EDLCs store charge non-faradically while redox capacitors use faradic method (Ryu et al., 2002). Different forms of carbon materials such as activated carbon, carbon aerogels and carbon nanotubes are employed in the formation of electrodes in EDLCs while transition metal oxides such as $\mathrm{RuO}_{\mathrm{x}}, \mathrm{CoO}, \mathrm{NiO}_{\mathrm{x}}$ or conducting polymers (CPs) such as Polypyrrole(PPY), Polyaniline (PANI) and Polythiophene (PT) are used for redox capacitors. CPs undergo oxidation and reduction (redox) processes and during those reactions, they store and release charges (Skaarup et al.,1998). This feature makes those polymers to be served as good electrode materials. Use of CP materials for redox capacitors has several advantages over other materials (Ramya et $a l ., 2013)$. They have good intrinsic conductivity, mechanical flexibility, chemical stability and are relatively cheap, so the preparation and fabrication costs would be low. There have been several recent reviews on the use of CPs for redox capacitors (Irvin and Iszard,2104; Ramya et al.,2013; Zhang et al.,2009; Jiao et al.,2011). A common issue of CPs for energy storage is a possible self-discharging, as charge carriers are the dopent and stored onto the polymer chain. This failure is extremely severe for some CPs such as Polyacetylene but moderate for PPY and PT. Among conventional CPs, self discharging of PANI is the lowest (Eftekhari et al., 2017). In addition to that, PANI has attracted much attention because of higher environmental 
stability, controllable electrical conductivity and easy processability (Sun et al.2002).

PANI exists as fully reduced leucoemeraldine (LE), half oxidized emeraldine base (EB) and fully oxidized pernigraniline (PE) states(Shimano and MacDiarmid,2001). The EB which is formed to Emaridine salt (ES) when doped in acidic medium, is regarded as the most useful form of PANI due to its high stability at room temperature. It is composed of two benzoid units and one quinoid unit and is known to be a semiconductor (Molapo et al.,2012).

The oxidation and reduction processes of PANI are accompanied by intercalation and deintercalation of counter-anions respectively. Since these processes are reversible, charge storage in PANI is facilitated to yield a pseudo capacitance behavior (Patil et al.,2014). Conditions used in the polymerization of PANI have very high contribution to the characteristics of the polymer (Bhadra et al.,2009). In this study, the effect of aniline concentration on the performance of PANI electrodes in a redox capacitor was investigated.

\section{EXPERIMENTAL}

\section{Preparation of electrodes}

The monomer aniline (Aldrich) was distilled and stored under refrigeration prior to use. Aniline was electrochemically polymerized on commercial grade stainless steel electrodes (type 304). For polymerization, a three electrode set up was used where $\mathrm{Ag} / \mathrm{AgCl}$ and Pt electrode were served as reference and counter electrodes respectively. The monomer (aniline) concentration was varied from $0.2 \mathrm{M}$ to $0.5 \mathrm{M}$. Concentrated sulfuric acid $\left(\mathrm{H}_{2} \mathrm{SO}_{4}\right.$ - Aldrich) of $0.5 \mathrm{M}$ was used as the oxidizing agent. It has several functions such as, to provide sufficiently low $\mathrm{pH}$ to dissolve aniline monomer in water and to avoid excessive branching of undesired products, but instead to generate doped ES form (Zotti et al.,1988). PANI films were galvanostatically polymerized using $1200 \mathrm{mC}$ $\mathrm{cm}^{-2}$ charge density. The area of working electrode was $1 \mathrm{~cm}^{-2}$. After polymerization, films were rinsed with distilled water and dried.

\section{Preparation of gel polymer electrolyte (GPE)}

Polyvinylidene fluoride (PVDF) (Aldrich), ethylene carbonate (EC) (98\%,Aldrich), propylene carbonate (PC) (99\%,Aldrich) and sodium thiocyanate (NaSCN) (99\%,Aldrich) were used as received. EC and PC weight ratio was fixed as 1:1. First, PVDF was dissolved in a EC, PC mixture with magnetic stirring. Then, NaSCN was added in to the mixture and stirring was continued until a homogeneous mixture was obtained. After that, the mixture was heated at $120{ }^{\circ} \mathrm{C}$ for 30 minutes. A very thin gel polymer film was obtained from the hot press method and it was left overnight in a vacuum desiccator (Jayathilake et al.,2015). The composition of the electrolyte was $16 \mathrm{PVDF} / 40 \mathrm{EC} / 40 \mathrm{PC} / 03$ $\mathrm{NaSCN}$ in weight basis.

\section{Fabrication of redox capacitors}

Sandwich-type symmetric redox capacitors were fabricated using two PANI electrodes. A GPE having the same area of electrode was used as the electrolyte. Structure of the redox capacitor was in the form of PANI / PVDF: EC: PC: NaSCN / PANI. Several redox capacitors were fabricated using electrodes prepared by varying aniline concentration.

\section{Characterization}

\section{Electrochemical Impedance Spectroscopy (EIS)}

EIS measurements of the redox capacitors were carried out within the frequency range from 400 $\mathrm{kHz}$ to $0.01 \mathrm{~Hz}$ using a frequency response analyzer (Metrohm AUTOLAB 101). Impedance data was analyzed using non - linear least square fitting program (Kumar and Munichandraiah,2000). Using the bode plots of capacitance versus frequency, the specific capacitance and relaxation constants $\left(\tau_{0}\right)$ were determined.

\section{Cyclic Voltammetry $(\mathrm{CV})$}

$\mathrm{CV}$ tests were performed in the potential window of $-0.2 \mathrm{~V}-0.8 \mathrm{~V}$ at the scan rate of $5 \mathrm{mVs}^{-1}$ by means of a computer controlled potentiostat / galvanostat (Metrohm-AUTOLAB 101). One PANI electrode was served as the working electrode and the other as both the counter and reference electrodes. Specific capacity $\left(\mathrm{C}_{\mathrm{s}}\right)$ was calculated using Eq. (1),

$$
C_{s}=\left(2 \int I d V\right) / m \Delta V S
$$

where $\int I d V$ is the area of the $C V, m$ is the mass of a single electrode, $\Delta V$ is the potential window and $S$ is the scan rate (Tey et al.,2016). 
Galvanostatic Charge-Discharge (GCD) test

Redox capacitor was first galvanostatically charged to $0.4 \mathrm{~V}$, immediately subjected to a galvanostatic discharge up to $0.0 \mathrm{~V}$. The galvanostatic charge and discharge currents were set to $800 \mu \mathrm{A}$. Discharge capacity $\left(C_{d}\right)$ was calculated using the Eq. (2),

$$
C_{d}=2 I /(m d V / d t)
$$

where, $I$ is the galvanostatic current, $\mathrm{m}$ is the mass of a single electrode, $d V$ is the potential drop during the discharge time $d t$ (Tey et al.,2016).

Energy density

$$
E=(1 / 2) C V^{2}
$$

and power density

$$
P=E / t
$$

were calculated using the data obtained from GCD test (Wang et al.,2013).

\section{RESULTS AND DISCUSSION}

\section{Polymerization}

In galvanostatic deposition, PANI deposited on stainless steel substrate was greenish in colour indicating formation of ES (Molapo et al.,2012). Monomer concentration was varied from $0.2 \mathrm{M}$ to $0.5 \mathrm{M}$, but good quality PANI films could be obtained only for the concentrations of $0.35 \mathrm{M}$, $0.40 \mathrm{M}$ and $0.45 \mathrm{M}$. Concentrations less than $0.35 \mathrm{M}$ gave very weak and soluble PANI films, while concentrations more than $0.45 \mathrm{M}$ pose a problem of monomer solubility in aqueous media.

\section{EIS data analysis}

By observing the Nyquist plots obtained by impedance data, the variation of charge transfer resistance and the bulk resistance with the aniline concentration of the PANI electrode can be determined. The high-frequency intercept of the semicircle on the real axis in the inset of Figure 1 provides the value of bulk electrolyte resistance $\left(R_{b}\right)$ and the diameter of the semicircle gives the value of the charge transfer resistance $\left(\mathrm{R}_{\mathrm{ct}}\right)$ (Prasad and Munichandraiah,2002). For $0.40 \mathrm{M}$ aniline, charge transfer resistance was nearly $1 \Omega$ and for the others it was high. The low charge transfer resistance of $0.40 \mathrm{M}$ electrode is an evidence for its suitability to use in redox capacitors.

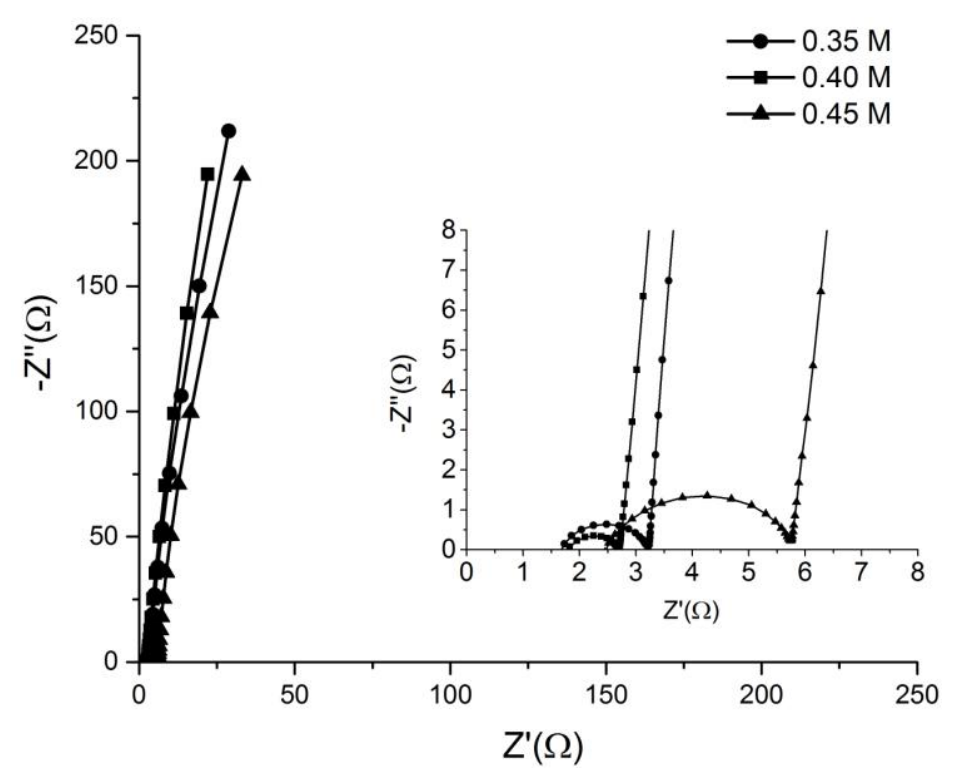

Figure 1: Nyquist plots within the frequency range of $400 \mathrm{KHz}$ to $0.01 \mathrm{~Hz}$ for the PANI /GPE /PANI redox capacitors fabricated using electrodes with different aniline concentrations. 


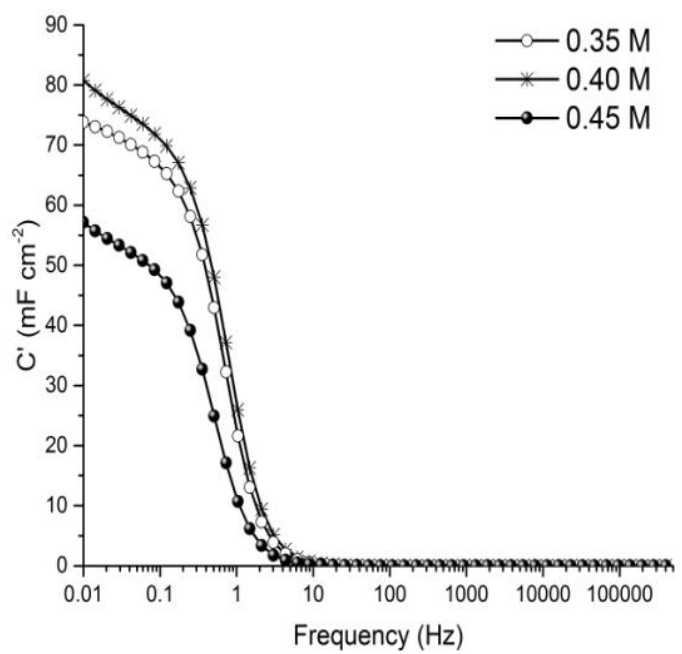

(a)

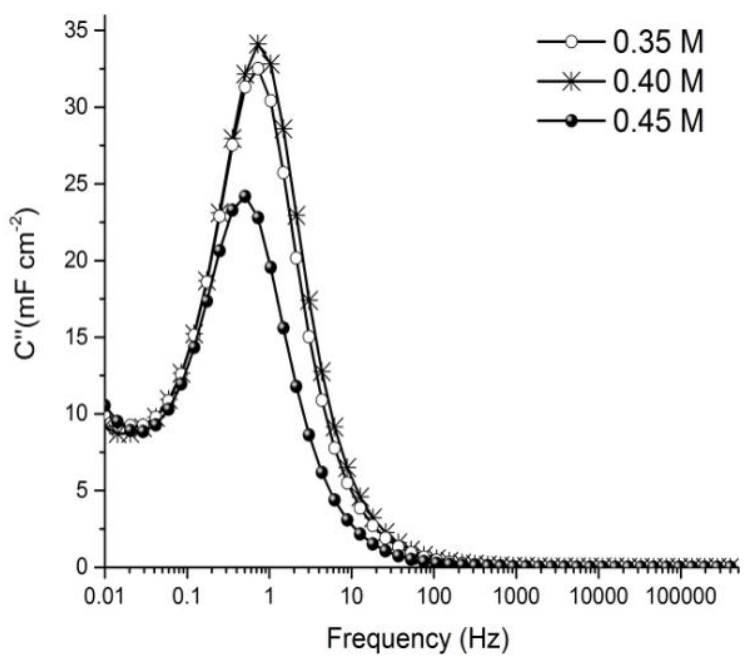

(b)

Figure 2: Bode plots for (a) real and (b) imaginary values of capacitance as a function of frequency in logarithmic scale. Three graphs represent the capacitors with different aniline concentrations.

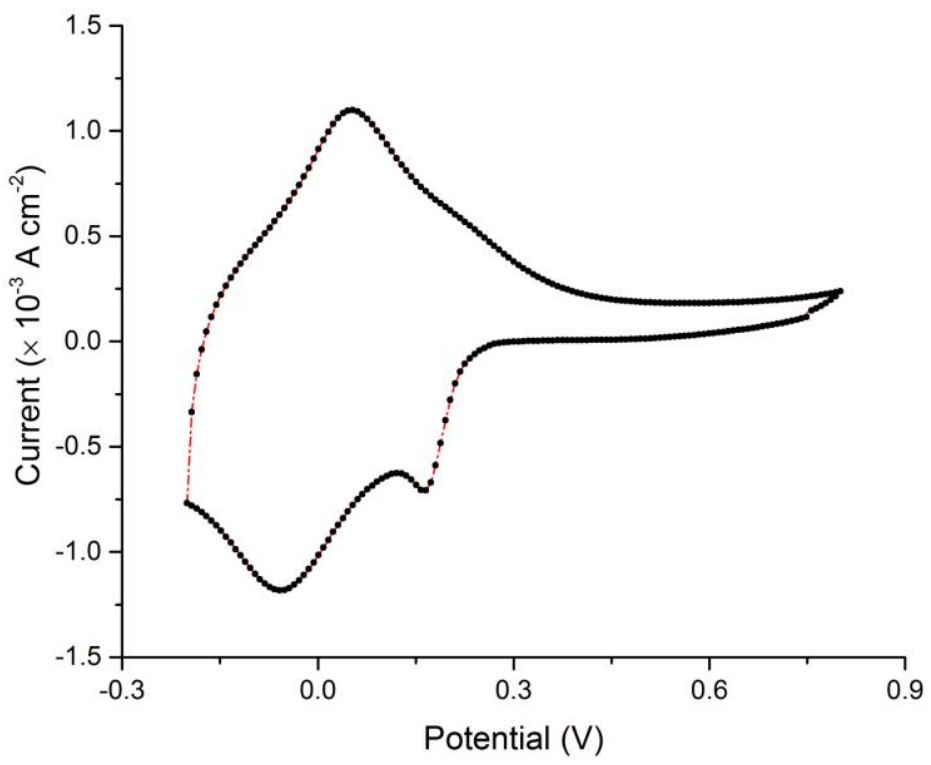

Figure 3: Cyclic voltammogram for the $10^{\text {th }}$ cycle of the PANI / GPE / PANI redox capacitor with $0.40 \mathrm{M}$ aniline concentration. Sweep rate is $5 \mathrm{mVs}^{-1}$.

At the low frequency range, electrodes exhibit a nearly vertical straight line of a limiting diffusion process which is a characteristic feature of pure capacitive behavior (Patil et al.,2014). Figure 2 (a), (b) show the Bode plots of the real part, $\mathrm{C}^{\prime}$ and imaginary part $\mathrm{C}^{\prime \prime}$ of the complex capacitance as a function of frequency.

In the low frequency region, capacitance of the electrode material is represented by C' and $0.40 \mathrm{M}$ capacitor shows the highest value of 80 $\mathrm{mF} \mathrm{cm}^{-2}$. Relaxation time constant, $\tau_{0}$ is a quantitative measure of the reversible charge- discharge speed of the redox capacitor (Prasad and Munichandraiah, 2002). Having the lowest value of $0.22 \mathrm{~s}$ for the $\tau_{0,}$ implies that $0.40 \mathrm{M}$ aniline system has the fastest ion movement behavior (Prasad and Munichandraiah, 2002, Tey et al.,2016).

\section{CV results}

Cyclic voltammograms of PANI redox capacitor obtained between $-0.2 \mathrm{~V}$ to $0.8 \mathrm{~V}$ are shown in Figure 3. It shows peaks corresponding to both the cathodic and anodic half-cycles as a result of 
redox processes that take place in the capacitor (Prasad and Munichandraiah,2002a).

Major redox peaks visible in the cyclic voltammograms can be attributed to oxidation/ reduction states of PANI (Jiao et al.,2011).

Figure 4 shows the specific capacity variation over 200 continuous cycling of PANI based redox capacitors with the variation of aniline concentration. Redox capacitor with 0.40 $\mathrm{M}$ aniline concentration recorded maximum specific capacity of $590 \mathrm{~F} \mathrm{~g}^{-1}$ while $0.35 \mathrm{M}$ and $0.45 \mathrm{M}_{\text {gave }} 560 \mathrm{~F} \mathrm{~g}^{-1}$ and $540 \mathrm{~F} \mathrm{~g}^{-1}$ respectively. Lack of full reversibility and less cycling efficiency are common features when side reactions are taking place. Consequently, the degradation of the capacity can be observed with the increment of the cycling number. However compared to other concentrations, $0.40 \mathrm{M}$ aniline redox capacitor maintained $81 \%$ of specific capacity retention from its initial value after 200 cycles.

\section{GCD test}

Figure 5 shows the GCD plots of PANI based redox capacitors having different aniline concentrations.

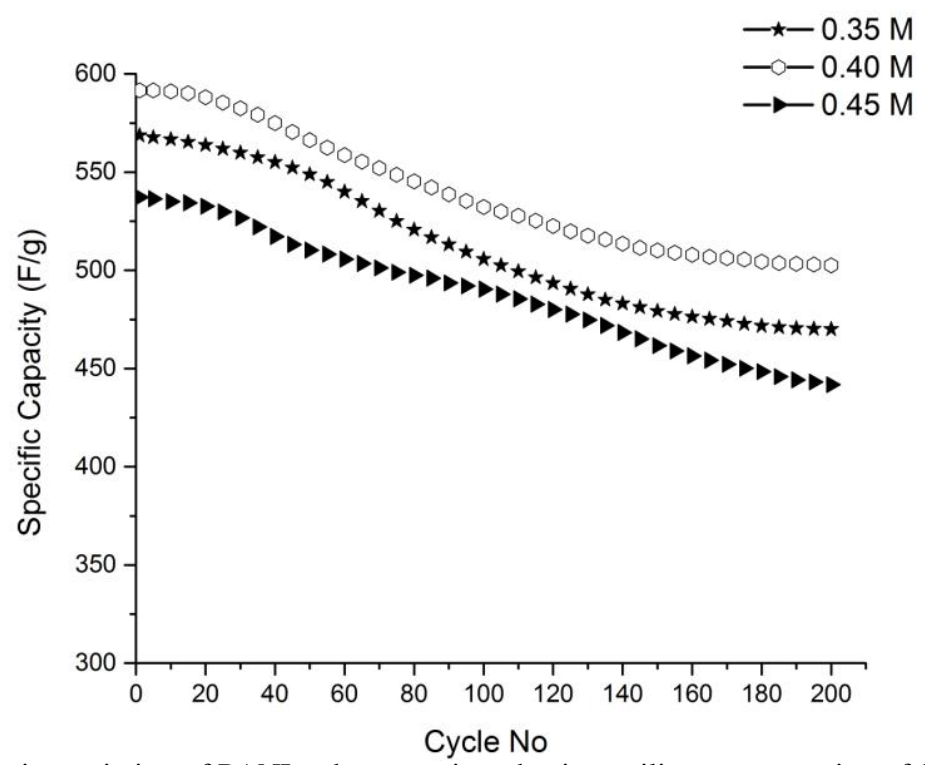

Figure 4: Specific capacity variation of PANI redox capacitors having aniline concentration of $0.35 \mathrm{M}, 0.40 \mathrm{M}$ and $0.45 \mathrm{M}$ obtained from cyclic voltammograms.

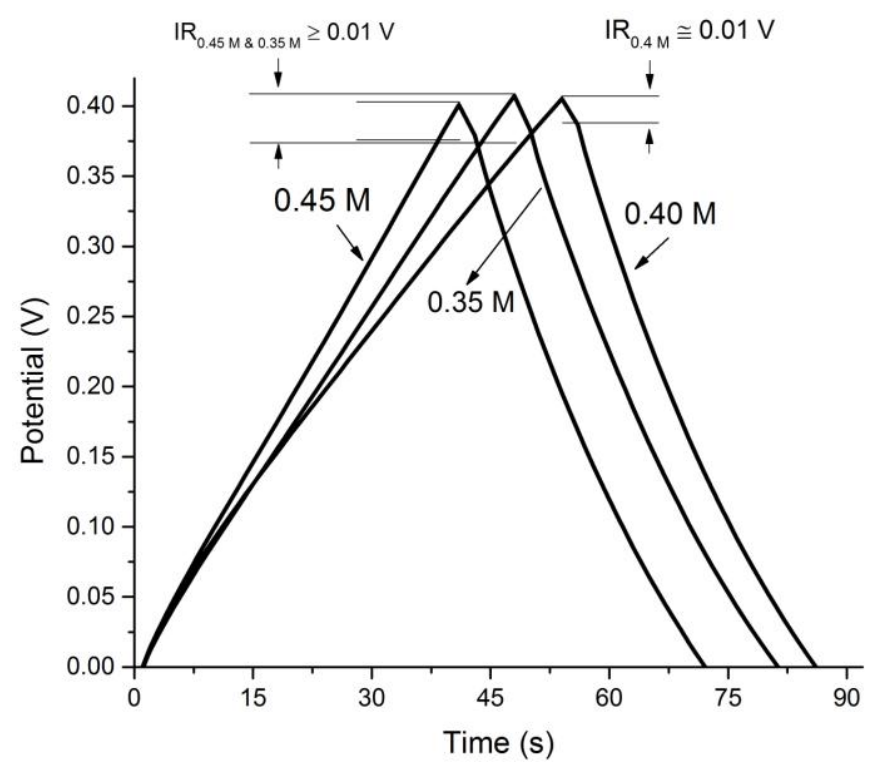

Figure 5: Galvanostatic charge-discharge curves of PANI based redox capacitors with different aniline concentrations. 
Table 1: Comparison of discharging capacity, power density and energy density with respect to variation of the Aniline concentration.

\begin{tabular}{cccc}
\hline Aniline concentration (M) & $\begin{array}{c}\text { Average discharge } \\
\text { capacity }\left(\mathbf{F ~}^{\mathbf{- 1}}\right)\end{array}$ & $\begin{array}{c}\text { Average power } \\
\text { density }\left(\mathbf{W ~} \mathbf{~ k g}^{-\mathbf{1}}\right)\end{array}$ & $\begin{array}{c}\text { Average energy } \\
\text { density }\left(\mathbf{W h} \mathbf{~ k g}^{-\mathbf{1}}\right)\end{array}$ \\
\hline 0.35 & 260 & 600 & 5.12 \\
\hline 0.40 & 323 & 760 & 6.50 \\
\hline 0.45 & 210 & 500 & 4.10 \\
\hline
\end{tabular}

Near linear and symmetric charge and discharge curves within the potential window of $0 \mathrm{~V}$ and $0.4 \mathrm{~V}$ indicates a very good capacitive performance with a rapid $\mathrm{I}-\mathrm{V}$ response (Wang $e t$ al.,2013). Also, the charge profile is symmetric illustrating a good capacitive behavior (Kulkarni et al.,2016). Curves show that lowest resistive drop (IR) of $0.01 \mathrm{~V}$ in the redox capacitor of 0.40 $\mathrm{M}$ aniline concentration and approximately 0.03 $\mathrm{V}$ for other concentrations.

Table 1 shows the comparison of the discharging capacity, power density and energy density after 1000 continuous GCD cycling of the three types of capacitors. According to that, $0.40 \mathrm{M}$ aniline based redox capacitor is having the highest values for discharge capacity, power density and energy density.

Results of above tests suggest that there exists a relationship between the concentration of the monomer, aniline with the specific capacity of the resultant PANI films. Bhadra et al. have reported that particle shape of the PANI films changes with the aniline concentration used during polymerization (Bhadra et al., 2017). Due to this change, there can be a variation in the porosity of PANI films which will directly relate to the electron movement. This may be the reason that the redox capacitor with PANI electrodes prepared with $0.4 \mathrm{M}$ aniline showed higher specific capacity than the other concentrations used.

\section{CONCLUSIONS}

Redox capacitors based on PANI electrodes were fabricated with varying aniline concentration and the effect of the monomer concentration on the capacity was investigated. EIS tests showed that redox capacitors have nearly ideal capacitive behavior. Cyclic voltammogram showed the good reversibility of the electrochemical systems and charge retention of $81 \%$ was recorded for $0.40 \mathrm{M}$ aniline based redox capacitor. GCD test performed for 1000 cycles resulted that capacitor having $0.40 \mathrm{M}$ aniline concentration can achieve an average discharge capacity of $323 \mathrm{~F} \mathrm{~g}^{-1}$, average power density of $760 \mathrm{~W} \mathrm{~kg}^{-1}$ and average energy density of $6.5 \mathrm{Wh} \mathrm{kg}^{-1}$. From the results of this study, it is evident that aniline concentration has a significant effect on the performance of PANI films when they are used as electrodes in redox capacitors.

\section{ACKNOWLEDGEMENT}

Authors wish to acknowledge the assistance provided by the National Science Foundation, Sri Lanka under the research grants RG/2014/BS/01, RG/2015/EQ/07and Wayamba University of Sri Lanka research grant SRHDC/RP/04/16-17( $\left.\mathrm{R}_{2}\right)$

\section{REFERENCES}

Bhadra, S., Khastgir, D., Singha, N. K., Lee, J. H. (2009) Progress in preparation, processing and applications of polyaniline, Prog. in Polymer Science (Oxford) 34;783-810.

Bhadra, J., Al-Thani, N.J., Madi, N.K., Al-Maadeed, M.A. (2017) Effects of aniline concentrations on the electrical and mechanical properties of polyaniline polyvinyl alcohol blends , Arabian Journal of Chemistry 10;664-672.

Eftekhari A., Li 1., Yang Y. (2017) Polyaniline super capacitors, Journal of Power Sources 347;86107.

Hashmi S. A., Ashok Kumar, Tripathi S. K. (2007) Experimental Studies on poly methyl methacrylate based gel polymer electrolyte for application in electrical double layer capacitors, Journal of Physics D: Applied Physics 40/21;6527-6534.

Irvin, J., Iszard, Z. (2014) Polymers for Charge Storage. In : Encyclopedia of Polymeric Nanomaterials, Springer, Verlag Berlin Heidelberg; 1-9.

Jayathilake, Y. M. C. D., Perera, K. S., Vidanapathirana, K. P. (2015) Preparation and characterization of a polyacrylonitrile-based gel polymer electrolyte complexed with 1 methyl-3 propyl immidazolium iodide. $J$ of Solid State Electrochemistry 19/8;2199-2203.

Jiao, S., Tu, J., Fan, C., Hou, J., Fray, D. J. (2011) Electrochemically Assembling of a Porous Nano- 
Polyaniline network in a reverse micelle and its application in a supercapacitor. Journal of Material Chemistry 21;9027-9030.

Kousksou, T., Bruel, P., Jamil, A., Elrhafiki, T., Zeraouli, Y. (2014) Energy storage: Applications and challenges, Solar Energy Materials \& Solar Cells 120;59-80.

Kulkarni, S. B., Patil, U. M., Shackery, I., Sohn, J. S., Lee, S., Park, B., Jun, S. (2014) HighPerformance Supercapacitor Electrode Based on a Polyaniline nano fibers /3D Graphene Framework as an Efficient Charge Transporter. Journal of Material Chemistry 14;4989-4998.

Kumar, G. G., Munichandraiah, N. (2000) A gel polymer electrolyte of magnesiumtriflate. Solid State Ionics 128;203-210.

Molapo, K. M., Ndangili, P.M., Ajayi, R. F., Mbambisa, G., Mailu, S. M., Njomo, N., Masikini, M., Baker, P., Iwuoha E. I. (2012) Electronics of Conjugated Polymers (I): Polyaniline. International Journal of Electrochemical Science 7;11859-11875.

Patil, D. S., Pawar, S. A., Devan, R. S., Mali, S. S., Gang, M. G., Ma, Y. R., Hong, C. K., Kim, J. H. (2014) Polyaniline based electrodes for electrochemical supercapacitor: Synergistic effect of silver, activated carbon and polyaniline. Journal of Electroanal Chemistry 724;21-28.

Prasad, K. R., Munichandraiah, N. (2002) Potentiodynamically deposited polyaniline on stainless steel. Journal of Electrochemical Society 149;A1393-A1399.

Prasad, K. R., Munichandraiah, N. (2002a) Electrochemical Studies of Polyaniline in a Gel Polymer Electrolyte. Electrochem and Solid State Letters 5;A271-A274.

Ramya, R., Sivasubramanian, R., Sangaranarayanan, M. V. (2013) Conducting polymers-based electrochemical supercapacitors-Progress and prospects, Electrochimica Acta 101;109-129.

Ryu, K. S., Kim, K. M., Park, N. G., Park, Y. J., Chang, S. H. (2002) Symmetric redox supercapacitor with conducting polyaniline electrodes. Journal of Power Sources 103;305309.

Shimano, J. Y. and MacDiarmid, A. G. (2001) Polyaniline, a dynamic block copolymer: key to attaining its intrinsic conductivity, Synthetic Metals, 123;251-262.

Skaarup, S., West K., Gunaratne, L. M. W. K., Vidanapathirana, K. P. (1998) Ionic motion in polypyrrole doped with ions of different sizes. In : Chowdari B.V.R. et al (ed) Solid State Ionics : Science and Technology, World Scientific Publishing Co. 163-171.

Sun, R. K., Man, K. K., Park, N. G., Park, Y. J., Chang, S. H. (2002) Symmetric Redox capacitor with conducting polyaniline electrodes, Journal of Power Sources 103/2;305-309.

Tey, J. P., Careem, M. A., Yarmo, M. A., Arof, A. K. (2016) Durian shell-based activated carbon electrode for EDLCs. Ionics 21/5;1-8.

Wang, W., Guo, S., Penchev, M., Ruiz, I., Bozhilov, K., Bozhilov, K. N., Yan, D., Ozkan, M., Ozkan, C. (2013) Three dimensional few layer graphene and carbon nanotube foam architectures for high fidelity supercapacitors. Nano Energy 2;294-303.

Zhang, Y., Feng, H., Wu, X., Wang, L., Zhang, A., Xia, T., Dong, H., Li, X., Zhang, L. (2009) Progress of Electrochemical Capacitor Electrode Materials: A Review. International Journal of Hydrogen Energy 34/11;4889-4899.

Zotti, G., Cattarin, S. and Comisso, N. (1988) Journal of Electroanal Chemistry 235;259-273. 